\title{
Factors associated with receipt of adjuvant chemotherapy among married women with breast cancer
}

Yan Zhang ${ }^{1}$, Hua Gao ${ }^{2}$, Yulan Bu', Xiuzhen Fan ${ }^{1 *}$ and Jihui Jia ${ }^{1 *}$

\begin{abstract}
Background: Adjuvant chemotherapies are recommended for most women after breast cancer surgery, and can greatly affect the patients' survival. We describe and evaluate possible factors influencing receipt of postoperative adjuvant chemotherapy among breast cancer patients in China.

Methods: A total of 1,431 women diagnosed with breast cancer from 1997 to 2005 were enrolled. We reviewed medical records and abstracted information about these patients. Details on social-demographic factors and clinical-pathological characteristics of participants were collected and analyzed. To meet our objectives, the patient's age at diagnosis, comorbidities, menstrual status, rural/urban status, tumor size, lymph node status, distant metastasis, tumor stage and hormone receptor status were estimated.

Results: Overall, 936 of these 1,431 patients (65.41\%) received adjuvant chemotherapy. Receipt of chemotherapy was significantly associated with age at diagnosis, rural-urban disparities, and lymph node status of patients, though no significant difference was found between the age $<50$ and age 50 to 64 groups. Moderate association was also observed between hormone receptor status and receipt of adjuvant chemotherapy, though it was still not statistically significant.

Conclusions: Our study suggests that age at diagnosis, rural-urban disparities and lymph node status of breast cancer patients are independent predictors for receipt of adjuvant chemotherapy among married Chinese women. Further investigations are warranted, and related public health education needs to be expanded in China.
\end{abstract}

Keywords: Breast cancer, Adjuvant chemotherapy, Epidemiology, Neoadjuvant chemotherapy

\section{Background}

Breast cancer has become the leading cause of cancer death among women in developing countries (for example, China), as well as the most diagnosed malignant tumor [1]. There are multiple strategies for breast cancer treatment, and adjuvant chemotherapy shows great benefit in reducing disease recurrence and improving prognosis for postoperative breast cancer patients [2,3]. Adjuvant chemotherapy is given after initial treatment with surgery, and is considered standard treatment for breast cancer patients [4-6]. Several studies have revealed that race, as well as marital status, may impact

\footnotetext{
* Correspondence: fxiuzhen@sdu.edu.cn; jiajihui@sdu.edu.cn 'Department of Nursing, Qilu Hospital and School of Nursing, Shandong University, West Wenhua Road, Ji'nan, Shandong 250012, P.R China Full list of author information is available at the end of the article
}

the receipt or completion of adjuvant chemotherapy among breast cancer patients [7-9]. We describe and evaluate possible factors influencing receipt of postoperative adjuvant chemotherapy among married yellow-race women with breast cancer in China.

\section{Methods}

Patients and data collection

Females diagnosed with primary breast cancer between 1 January 11997 and 31 December 2005 and who received surgery treatment post-diagnosis in Qilu Hospital were collected as candidates. All cases are yellow race, married females who met clinical criteria for consideration of adjuvant chemotherapy. We retrieved and identified information from medical records. To meet our objectives, social-demographic factors and clinical-

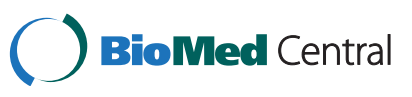


pathological characteristics of candidates including patient's age at diagnosis, comorbidities, menstrual status, rural/urban status, tumor size, lymph node status, distant metastasis, tumor stage, hormone receptor status, race, marital status, and others were abstracted.

Breast cancer cases were identified by operation and histopathological examination. Clinical-pathological parameters such as estrogen receptor (ER) and progestogen receptor (PR) were evaluated by immunological histological chemistry staining. Cases were scored positive when $\geq 10 \%$ of the tumor cells on the slide showed positive staining irrespective of staining intensity. Operating procedures were classified into radical mastectomy, modified radical mastectomy and breast/nipple conserving surgery. Rurality was defined according to the socioeconomic survey team of the National Bureau of Statistics of China [10]. Comorbid illness includes cardiovascular diseases, rheumatism, tuberculosis, liver disease and other chronic diseases excluding previous or current malignant tumors that were reported by patients or their relatives. Patients without menses for more than six months were classified as postmenopausal cases. All variables were measured as of the time of treatment. Studies have shown that receipt of neoadjuvant chemotherapy may influence decisions about adjuvant chemotherapy $[7,11,12]$. As a result, whether a patient had received neoadjuvant chemotherapy was identified and classified.

Data collection was performed independently by two individuals. Patients' information was abstracted and coded anonymously for all participants in the study. Written, informed consent was obtained as delineated by the protocol, which was approved by the ethical committee of Shandong University.

\section{Statistical analyses}

We conducted univariate analyses with each of these explanatory variables using Chi-square $\left(\chi^{2}\right)$ tests accompanied by two-sided $P$ values. A multivariate logistic regression model evaluated the association between predictors and receipt of adjuvant chemotherapy. Because the factors that affect delivery of neoadjuvant chemotherapy are probably similar to those that affect adjuvant chemotherapy, we removed parameters of neoadjuvant chemotherapy from the multivariate analyses. Logistic regression outcomes were expressed as adjusted odds ratios (OR), with 95\% confidence intervals (CI). For estrogen receptor/progestogen receptor (ER/PR) status, the predictor variable showed a significant number of missing values; therefore, we re-estimated the relevant model as a sensitivity test. All the statistics were performed using the PASW Statistics 18.0 software (SPSS Inc. Chicago, Illinois, USA), and were based on twotailed probability. $P$ values of $<0.05$ were considered statistically significant.

\section{Results}

During the period from 1 January 1997 to 31 December 2005 , a total of 1,431 married women who were diagnosed with invasive breast cancer (pTNM stage I - IV) and who received breast surgery in Qilu Hospital was included in our analyses. Overall, 936 of these 1,431 patients (65.41\%) received adjuvant chemotherapy, and patients' social-demographic and clinical-pathological characteristics were described in Table 1 . We included possible predictors into our univariate analyses, as shown in Table 2. The percentage of rural women who received chemotherapies was significantly lower when compared with urban females $(61.15 \%$ versus $67.38 \%$, $P=0.021)$. Meanwhile, our results showed that receipt of chemotherapy was significantly associated with patient's age at diagnosis $(P=0.030)$, with older females receiving less adjuvant chemotherapy. Whether a patient received neoadjuvant chemotherapy was related to the final decision of receipt of adjuvant chemotherapy or not $(P<0.001)$. Importantly, outcomes demonstrated that lymph node status of patients was highly associated with their final decision about receipt of adjuvant chemotherapy $(P<0.001)$. In these unadjusted analyses, no significant association was found between comorbid status, menopausal status, tumor size, distant metastasis or tumor stage and receipt of chemotherapy. Moderate association was observed between hormone receptor status and receipt of chemotherapy, with a $P$ value of 0.082 .

Then we estimated the adjusted values by controlling covariates using multivariate logistic regression model, as shown in Table 3. Interestingly, the statistical pattern of result did not change, and the significant association demonstrated in the univariate analyses still existed in the multivariate analyses, with the exception of neoadjuvant status, a parameter that had been removed from the analytic models. Receipt of chemotherapy was significantly associated with age at diagnosis, ruralurban disparities, and lymph node status of patients. The difference between age $<50$ and age $\geq 70$ was significant $(\mathrm{OR}=0.407,95 \% \mathrm{CI}=0.209$ to $0.792, P=0.008)$, though no significant difference was found between age $<50$ and age 50 to 64 groups $(P=0.319)$. More urban females received adjuvant chemotherapy than rural ones after adjusting $\mathrm{r}$ other parameters $(\mathrm{OR}=1.381,95 \%$ $\mathrm{CI}=1.083$ to $1.761, P=0.009$ ). Patients with positive lymph node metastases received adjuvant chemotherapy more often than patients with negative cases of lymph node metastases $(\mathrm{OR}=1.600,95 \% \mathrm{CI}=1.266$ to 2.022 , $P<0.001)$. Moderate association was also observed between hormone receptor status and receipt of adjuvant chemotherapy, though it was still not statistically significant $(P=0.066)$. Because ER/PR status is an important pathological factor and because observations on this variable were missing for $38.71 \%$ of the cases, we 
Table 1 Demographic and clinical characteristics of breast cancer patients

\begin{tabular}{|c|c|}
\hline Variable & Number of cases $(\mathrm{N}=1,431)$ \\
\hline \multicolumn{2}{|l|}{ Age at diagnosis (years) } \\
\hline$<50$ & 780 \\
\hline 50 to 69 & 572 \\
\hline$\geq 70$ & 79 \\
\hline \multicolumn{2}{|c|}{ Neoadjuvant chemotherapy received } \\
\hline No & 1,075 \\
\hline Yes & 356 \\
\hline \multicolumn{2}{|l|}{ Comorbidities } \\
\hline None & 1,024 \\
\hline One or more & 407 \\
\hline \multicolumn{2}{|l|}{ Menopausal status } \\
\hline Premenopause & 703 \\
\hline Menopause & 728 \\
\hline \multicolumn{2}{|l|}{ Residential status } \\
\hline Rural & 453 \\
\hline Urban & 978 \\
\hline \multicolumn{2}{|l|}{ Smoking } \\
\hline Previous or current & 13 \\
\hline Never or no report & 1,418 \\
\hline \multicolumn{2}{|l|}{ Reasons for visit } \\
\hline Self-examination & 1,404 \\
\hline Physical examination & 27 \\
\hline \multicolumn{2}{|l|}{ Tumor size } \\
\hline$\leq 2$ & 1,088 \\
\hline$>2$ & 214 \\
\hline \multicolumn{2}{|l|}{ Lymph node metastasis } \\
\hline Negative & 823 \\
\hline Positive & 606 \\
\hline \multicolumn{2}{|l|}{ Distant metastasis } \\
\hline Negative & 1,421 \\
\hline Positive & 10 \\
\hline \multicolumn{2}{|l|}{ Tumor stage } \\
\hline I & 178 \\
\hline$\|$ & 927 \\
\hline III & 198 \\
\hline IV & 10 \\
\hline \multicolumn{2}{|l|}{ Hormone receptor status } \\
\hline ER- and PR- & 203 \\
\hline ER + and/or PR+ & 648 \\
\hline \multicolumn{2}{|l|}{ Histological type } \\
\hline IDC & 1,164 \\
\hline ILC & 49 \\
\hline Others & 218 \\
\hline
\end{tabular}

Table 1 Demographic and clinical characteristics of breast cancer patients (Continued)

\begin{tabular}{lc}
\hline Procedure & \\
Radical mastectomy & 503 \\
Modified radical mastectomy & 828 \\
Breast/nipple conserving surgery & 55 \\
NOS & 45 \\
Treatment & \\
Surgery & 1,431 \\
Radiotherapy & 11 \\
Endocrinotherapy & 264 \\
Chemotherapy & 936 \\
NOS & 496
\end{tabular}

ER, estrogen receptor; $P R$, progestogen receptor; IDC, invasive ductal carcinoma; ILC, invasive lobular carcinoma; NOS, not otherwise specified.

performed a sensitivity analysis to verify our result (not shown). We re-estimated the logistic regression model (1) by excluding hormone receptor (ER/PR) status or (2) by only accepting the remaining 887 patients with ER/ PR information. No change in sign or patterns of statistical significance was found for any of them.

Previous studies have mentioned that receipt of neoadjuvant chemotherapy could influence a patient's decisions about receipt of adjuvant chemotherapy $[7,11,12]$. Consequently, we excluded patients who had received neoadjuvant chemotherapy (as have other studies mentioned above) and re-estimated the logistic regression model in Table 4. Overall, 1,075 patients were included, and there were no changes in sign or patterns of statistical significance for any of the parameters. Because the factors that affect delivery of neoadjuvant chemotherapy are probably similar to those that affect adjuvant chemotherapy, and because women get all of their chemotherapy as neoadjuvant in some countries, we also re-estimate our analytic model by combining neoadjuvant and/or adjuvant chemotherapy as dependent variables, as shown in Table 5. A moderately significant association was observed between rural-urban disparities and receipt of adjuvant chemotherapy, with a $P$ value of 0.072 . No changes in sign or patterns of statistical significance were observed for the remaining factors.

All the logistic regression models adopted in this study exhibited high goodness-of-fit, with a Hosmer-Lemeshow goodness-of-fit $P$ value of 0.996 in Table 3 and above 0.500 in all logistic models.

\section{Discussion}

Receipt of proper adjuvant chemotherapy for breast cancer patients is very important and associated with prognosis of breast cancer patients. Both clinical trials and 
Table 2 Univariate analysis of demographic and clinical factors associated with receipt of adjuvant chemotherapy

\begin{tabular}{lcc}
\hline Variable & $\begin{array}{c}\text { Number } \\
\text { of cases } \\
(\mathrm{N}=1,431)\end{array}$ & $\begin{array}{c}\text { Percent that received } \\
\text { adjuvant chemotherapy } \\
(\mathrm{N}=936)\end{array}$ \\
\hline
\end{tabular}

Age at diagnosis (years)

$\begin{array}{lccc}<50 & 780 & 79.62 \% & 0.030 \\ 50 \text { to } 69 & 572 & 65.38 \% & \\ \geq 70 & 79 & 51.90 \% & \end{array}$

Neoadjuvant

chemotherapy received

$\begin{array}{lcc}\text { No } & 1,075 & 60.28 \% \\ \text { Yes } & 356 & 80.90 \%\end{array}$

\section{Comorbidities}

None $\quad 1,024$

One or more

$$
1,024
$$

Menopausal status

Premenopause

Menopause

Residential status

$\begin{array}{ll}\text { Rural } & 45 \\ \text { Urban } & 978\end{array}$

Tumor size

$\leq 2 \quad 1,088$

$>2$

Lymph node metastasis

Negative

Positive

\section{3}

606

Distant metastasis

\section{Negative}

Positive

Tumor stage

$$
\text { । }
$$

॥

III

IV

Hormone receptor status

$\begin{array}{lll}\text { ER- } \text { and PR- } & 203 & 61.58 \% \\ \text { ER }+ \text { and/or PR+ } & 648 & 71.91 \%\end{array}$

$\mathrm{ER}$, estrogen receptor; $\mathrm{PR}$, progestogen receptor.

consensus guidelines have identified subsets of women with breast cancer who are able to gain benefit from adjuvant chemotherapy [4,13-15]. Many factors, including age, comorbidities, marital status, variation in provider recommendation, medical insurance, and life expectancy, are associated with whether women receive adjuvant chemotherapy and have been reported for a long time [12,16-20]. Married women usually enjoy overall
Table 3 Logistic regression analysis of demographic and clinical factors associated with receipt of adjuvant

\begin{tabular}{|c|c|c|c|}
\hline Variable & $\mathrm{OR}^{\mathrm{a}}$ & $95 \% \mathrm{Cl}^{\mathrm{a}}$ & Adjusted $P^{\mathrm{a}}$ \\
\hline \multicolumn{4}{|c|}{ Age at diagnosis (years) } \\
\hline$<50$ & Referent & & \\
\hline 50 to 69 & 0.769 & 0.463 to 1.275 & 0.308 \\
\hline$\geq 70$ & 0.410 & 0.212 to 0.793 & 0.008 \\
\hline \multicolumn{4}{|l|}{ Comorbidities } \\
\hline None & Referent & & \\
\hline One or more & 1.033 & 0.791 to 1.349 & 0.811 \\
\hline \multicolumn{4}{|l|}{ Menopausal status } \\
\hline Premenopause & Referent & & \\
\hline Menopause & 1.205 & 0.734 to 1.979 & 0.461 \\
\hline \multicolumn{4}{|l|}{ Residential status } \\
\hline Rural & Referent & & \\
\hline Urban & 1.381 & 1.083 to 1.761 & 0.009 \\
\hline \multicolumn{4}{|l|}{ Tumor size } \\
\hline$\leq 2$ & Referent & & \\
\hline$>2$ & 0.828 & 0.603 to 1.136 & 0.242 \\
\hline \multicolumn{4}{|c|}{ Lymph node metastasis } \\
\hline Negative & Referent & & \\
\hline Positive & 1.600 & 1.266 to 2.022 & $<0.001$ \\
\hline \multicolumn{4}{|l|}{ Distant metastasis } \\
\hline Negative & Referent & & \\
\hline Positive & 1.123 & 0.282 to 4.475 & 0.869 \\
\hline \multicolumn{4}{|c|}{ Hormone receptor status } \\
\hline ER- and PR- & Referent & & \\
\hline$E R+$ and/or PR+ & 1.364 & 0.979 to 1.900 & 0.066 \\
\hline
\end{tabular}
chemotherapy

${ }^{a}$ Adjusted using multivariate logistic regression model.

$\mathrm{ER}$, estrogen receptor; PR, progestogen receptor; $\mathrm{OR}$, odds ratios; $\mathrm{Cl}$, confidence intervals.

better health and higher socioeconomic status than unmarried ones, which may translate into better access to healthcare and other benefits. Meanwhile, marriage may reflect a healthy selection bias, and one study has reported that those with psychiatric or physical impairments may be less likely to marry [21]. Marriage may also influence the lifestyle and behaviors of women, including diet, exercise, and health screening, which may be mediating factors when making better medical choices [22]. On the other hand, marriage could offer better social support networks [23], indicating better financial support and receipt of more sensible advice, which could influence a woman's choice about receipt of adjuvant chemotherapy. Considering that most of our candidates were married, this study only focused on married women to reduce bias resulting from these confounding factors. Our research focused on married Chinese women who met clinical 
Table 4 Logistic regression analysis of factors associated with receipt of adjuvant chemotherapy among patients not receiving neoadjuvant chemotherapy

\begin{tabular}{|c|c|c|c|}
\hline Variable & $O R^{a}$ & $95 \% \mathrm{Cl}^{\mathrm{a}}$ & Adjusted $P^{a}$ \\
\hline \multicolumn{4}{|c|}{ Age at diagnosis (years) } \\
\hline$<50$ & Referent & & \\
\hline 50 to 69 & 0.690 & 0.386 to 1.234 & 0.211 \\
\hline$\geq 70$ & 0.303 & 0.143 to 0.643 & 0.002 \\
\hline \multicolumn{4}{|l|}{ Comorbidities } \\
\hline None & Referent & & \\
\hline One or more & 1.090 & 0.810 to 1.467 & 0.568 \\
\hline \multicolumn{4}{|l|}{ Menopausal status } \\
\hline Premenopause & Referent & & \\
\hline Menopause & 1.374 & 0.778 to 2.428 & 0.274 \\
\hline \multicolumn{4}{|l|}{ Residential status } \\
\hline Rural & Referent & & \\
\hline Urban & 1.398 & 1.058 to 1.846 & 0.018 \\
\hline \multicolumn{4}{|l|}{ Tumor size } \\
\hline$\leq 2$ & Referent & & \\
\hline$>2$ & 0.799 & 0.510 to 1.150 & 0.198 \\
\hline \multicolumn{4}{|c|}{ Lymph node metastasis } \\
\hline Negative & Referent & & \\
\hline Positive & 1.383 & 1.057 to 1.809 & 0.018 \\
\hline \multicolumn{4}{|l|}{ Distant metastasis } \\
\hline Negative & Referent & & \\
\hline Positive & 1.908 & 0.191 to 19.015 & 0.582 \\
\hline \multicolumn{4}{|c|}{ Hormone receptor status ${ }^{\mathrm{a}}$} \\
\hline ER- and PR- & Referent & & \\
\hline ER + and/or PR+ & 1.425 & 0.981 to 2.070 & 0.063 \\
\hline
\end{tabular}

${ }^{a}$ Adjusted using multivariate logistic regression model.

$\mathrm{ER}$, estrogen receptor; PR, progestogen receptor; $\mathrm{OR}$, odds ratios; $\mathrm{Cl}$, confidence intervals.

criteria for adjuvant chemotherapy, and analyzed the possible predictors about receipt of adjuvant chemotherapy. Though the recommendations and protocols for adjuvant chemotherapy changed over this period, an inpatient who was recommended for chemotherapy but refused doctors' advice would be recorded for the purpose of preventing medical accidents, so we were able to select candidates for this study. For now, only patients with invasive breast cancers are recommended for adjuvant chemotherapy generally, and we performed secondary selection only accepting patients diagnosed with invasive breast cancers, in line with current research. Because health care in China is a government-run project and most of our patients on record were covered by this basic medical insurance system, we did not take individual financial income of breast cancer patients into consideration.
Table 5 Logistic regression analysis of demographic and clinical factors associated with receipt of adjuvant and/or neoadjuvant chemotherapy

\begin{tabular}{|c|c|c|c|}
\hline Variable & $\mathrm{OR}^{\mathrm{a}}$ & $95 \% \mathrm{Cl}^{\mathrm{a}}$ & Adjusted $P^{\mathrm{a}}$ \\
\hline \multicolumn{4}{|c|}{ Age at diagnosis (years) } \\
\hline$<50$ & Referent & & \\
\hline 50 to 69 & 0.701 & 0.407 to 1.207 & 0.200 \\
\hline$\geq 70$ & 0.337 & 0.169 to 0.674 & 0.002 \\
\hline \multicolumn{4}{|l|}{ Comorbidities } \\
\hline None & Referent & & \\
\hline One or more & 1.075 & 0.813 to 1.420 & 0.613 \\
\hline \multicolumn{4}{|l|}{ Menopausal status } \\
\hline Premenopause & Referent & & \\
\hline Menopause & 1.319 & 0.773 to 2.249 & 0.310 \\
\hline \multicolumn{4}{|l|}{ Residential status } \\
\hline Rural & Referent & & \\
\hline Urban & 1.265 & 0.979 to 1.633 & 0.072 \\
\hline \multicolumn{4}{|l|}{ Tumor size } \\
\hline$\leq 2$ & Referent & & \\
\hline$>2$ & 1.266 & 0.888 to 1.804 & 0.192 \\
\hline \multicolumn{4}{|c|}{ Lymph node metastasis } \\
\hline Negative & Referent & & \\
\hline Positive & 1.933 & 1.508 to 2.477 & $<0.001$ \\
\hline \multicolumn{4}{|l|}{ Distant metastasis } \\
\hline Negative & Referent & & \\
\hline Positive & 2.639 & 0.326 to 21.335 & 0.363 \\
\hline \multicolumn{4}{|c|}{ Hormone-receptor status } \\
\hline ER- and PR- & Referent & & \\
\hline $\mathrm{ER}+$ and/or PR+ & 1.392 & 0.986 to 1.964 & 0.060 \\
\hline
\end{tabular}

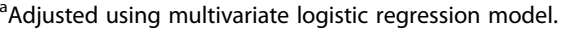

$\mathrm{ER}$, estrogen receptor; PR, progestogen receptor; $\mathrm{OR}$, odds ratios; $\mathrm{Cl}$, confidence intervals.

In the univariate analyses, we found that $65.41 \%$ of the patients in this research have received postoperative adjuvant chemotherapy. Age at diagnosis, rural-urban disparities, and receipt of neoadjuvant chemotherapy or not, significantly associated with the final decision of patients about the receipt of adjuvant chemotherapy, as shown in Table 2. After being controlled for covariates, the differences still existed and no change in sign or patterns of statistical significance was observed in all participants and cases without receipt of neoadjuvant chemotherapy only, as shown in Table 3 and Table 4, respectively.

Age of patients is associated with receipt of adjuvant chemotherapy and has been studied for a long time [3,11,16,24-26]. Our data revealed that older women adopt adjuvant chemotherapy less than young women, especially women at least 70 years old. In the clinic, 
older patients are less likely to tolerate chemotherapy and more likely to adopt more conservative treatment for a better quality of remaining life, consistent with clinical reports and consensus guidelines [14,24,27]. We also found that more urban women adopted adjuvant chemotherapy than rural ones, and the difference is statistically significant. Rural-urban disparities have an influence on many aspects for Chinese females, especially on education, life style, income and so forth, and urban women usually receive a better education and make more money. All of these could result in urban women knowing the benefit of adjuvant chemotherapy better, being more willing and able to pay for their health, and being able to endure the pain and chemotherapy.

As mentioned in previous studies, receipt of neoadjuvant chemotherapy may influence the decisions about adjuvant chemotherapy $[7,11]$. Our results indicate that patients who received neoadjuvant chemotherapy are more likely to receive postoperative chemotherapy $(80.90 \%$ versus $60.28 \%$, $P<0.001)$. Because the factors that affect delivery of neoadjuvant chemotherapy are probably similar to those that affect adjuvant chemotherapy, we re-estimated the predictors among females without receipt of neoadjuvant chemotherapy or combined neoadjuvant and/or adjuvant chemotherapy as one dependent variable. After that we still had similar results, which verify the predictors discovered in our analyses.

\section{Strengths and weaknesses}

First, chemotherapy regimens adopted by patients in our study consist of CMF, CTX, CEF and so forth, and we did not include chemotherapy regimens as parameters in our analyses. However, it would make our analytic models overly complicated and affect the accuracy and stability of our results since many patients accepted chemotherapy with multiple regiments. Second, a significant number of predictor values (ER and PR status) were missing in the multivariate analytic models. Nonetheless, we re-estimated the relevant model by excluding hormone-receptor (ER/PR) status or by only accepting the remaining 887 patients with ER/PR information in the analyses, and found no change in sign or patterns of statistical significance for any of them.

\section{Conclusions}

Recently the importance of understanding patients who did or did not receive advised adjuvant chemotherapy was highlighted and discussed $[3,7,8]$. Studies have discovered that whether a patient who met clinical criteria for adjuvant chemotherapy accepted it or not, is associated with human race, marital status, socioeconomic status, and some other demographic factors. In this study, we collected information on female breast cancer patients who are yellow race and married, and explored the predictors about receipt of adjuvant chemotherapy. Our study suggests that age at diagnosis, rural-urban disparities and lymph node status of breast cancer patients are independent predictors for the receipt of adjuvant chemotherapy among married Chinese women. Further investigations are warranted, and related public health education needs to be expanded in China.

\section{Abbreviations}

$\mathrm{Cl}$ : Confidence interval; ER: Estrogen receptors; IDC: Invasive ductal carcinoma; ILC: Invasive lobular carcinoma; NOS: Not otherwise specified; OR: Odds ration; PR: Progestogen receptor.

\section{Competing interests}

The authors declare that they have no competing interests.

\section{Authors' contributions}

$Y Z, X F$ and $J J$ conceived of the study and drafted and revised the manuscript. $Y Z, H G$ and $Y B$ carried out the data collection and the statistical analysis. All authors read and approved the final manuscript.

\section{Acknowledgements}

We thank all medical staff in the Department of Breast Surgery, Qilu Hospital, for support and critical discussions.

\section{Author details}

${ }^{1}$ Department of Nursing, Qilu Hospital and School of Nursing, Shandong University, West Wenhua Road, Ji'nan, Shandong 250012, P.R China.

${ }^{2}$ Tianchen Hospital of Zaozhuang Mining Group, Tianchen Town, Zaozhuang City 277500, P.R China.

Received: 14 January 2013 Accepted: 18 October 2013 Published: 31 October 2013

\section{References}

1. Jemal A, Bray F, Melissa M, Ferlay J, Ward E, Forman D: Global cancer statistics. CA Cancer J Clin 2011, 61:69-90

2. Bonadonna G, Valagussa P: Dose-response effect of adjuvant chemotherapy in breast cancer. N Engl J Med 1981, 304:10-15.

3. Muss HB, Berry DA, Cirrincione CT, Theodoulou M, Mauer AM, Kornblith AB, Partridge AH, Dressler LG, Cohen HJ, Becker HP, Kartcheske PA, Wheeler JD, Perez EA, Wolff AC, Gralow JR, Burstein HJ, Mahmood AA, Magrinat G, Parker BA, Hart RD, Grenier D, Norton L, Hudis CA, Winer EP, CALGB Investigators: Adjuvant chemotherapy in older women with early-stage breast cancer. N Engl J Med 2009, 360:2055-2065.

4. Consensus NIH: Statement. Adjuvant Therapy for Breast Cancer 2000, 17:1-35.

5. Consensus conference: Adjuvant chemotherapy for breast cancer. JAMA 1985, 254:3461-3463

6. NIH consensus conference: Treatment of early-stage breast cancer. JAMA 1991, 265:391-395.

7. Lipscomb J, Gillespie TW, Goodman M, Richardson LC, Pollack LA, Ryerson AB, Ward KC: Black-white differences in receipt and completion of adjuvant chemotherapy among breast cancer patients in a rural region of the US. Breast Cancer Res Treat 2012, 133:285-296.

8. Hershman DL, Unger JM, Barlow WE, Hutchins LF, Martino S, Osborne CK, Livingston RB, Albain KS: Treatment quality and outcomes of African American versus white breast cancer patients: retrospective analysis of Southwest Oncology studies S8814/S8897. J Clin Oncol 2009, 27:2157-2162.

9. Bickell NA, Wang JJ, Oluwole S, Schrag D, Godfrey H, Hiotis K, Mendez J, Guth AA: Missed opportunities: racial disparities in adjuvant breast cancer treatment. J Clin Oncol 2006, 24:1357-1362.

10. China. SstoNBoSo: Fifty years of cities of People's Republic of China. Beijing: Xinhua Press; 1999

11. Giordano SH, Duan Z, Kuo YF, Hortobagyi GN, Goodwin JS: Use and outcomes of adjuvant chemotherapy in older women with breast cancer. J Clin Oncol 2006, 24:2750-2756.

12. Richardson LC, Tian L, Voti L, Hartzema AG, Reis I, Fleming LE, Mackinnon J: The roles of teaching hospitals, insurance status, and race/ethnicity in 
receipt of adjuvant therapy for regional-stage breast cancer in Florida. Am J Public Health 2006, 96:160-166.

13. Glick JH, Gelber RD, Goldhirsch A, Senn HJ: Adjuvant therapy of primary breast cancer. 4th International Conference on Adjuvant Therapy of Primary Breast Cancer St. Gallen, Switzerland. Ann Oncol 1992, 3:801-807.

14. Goldhirsch A, Glick JH, Gelber RD, Coates AS, Senn HJ: Meeting highlights: international consensus panel on the treatment of primary breast cancer. Seventh international conference on adjuvant therapy of primary breast cancer. J Clin Oncol 2001, 19:3817-3827.

15. Rao RD, Cobleigh MA: Adjuvant endocrine therapy for breast cancer. Oncology (Williston Park) 2012, 26:541-547. 550, 552 passim.

16. Silliman RA, Guadagnoli E, Weitberg AB, Mor V: Age as a predictor of diagnostic and initial treatment intensity in newly diagnosed breast cancer patients. J Gerontol 1989, 44:M46-M50.

17. Du XL, Key CR, Osborne C, Mahnken JD, Goodwin JS: Discrepancy between consensus recommendations and actual community use of adjuvant chemotherapy in women with breast cancer. Ann Intern Med 2003, 138:90-97.

18. Bickell NA, Aufses AH Jr, Chassin MR: The quality of early-stage breast cancer care. Ann Surg 2000, 232:220-224.

19. Breen N, Wesley MN, Merrill RM, Johnson K. The relationship of socio-economic status and access to minimum expected therapy among female breast cancer patients in the National Cancer Institute Black-White Cancer Survival Study. Ethn Dis 1999, 9:111-125.

20. Bradley CJ, Given CW, Roberts C: Race, socioeconomic status, and breast cancer treatment and survival. J Natl Cancer Inst 2002, 94:490-496.

21. Kisker EE, Goldman N: Perils of single life and benefits of marriage. Soc Biol 1987, 34:135-152.

22. Kravdal O: The impact of marital status on cancer survival. Soc Sci Med 2001, 52:357-368.

23. Bloom JR, Stewart SL, Johnston M, Banks P, Fobair P: Sources of support and the physical and mental well-being of young women with breast cancer. Soc Sci Med 2001, 53:1513-1524.

24. Du X, Goodwin JS: Patterns of use of chemotherapy for breast cancer in older women: findings from Medicare claims data. J Clin Oncol 2001, 19:1455-1461

25. Buist DS, Chubak J, Prout M, Yood MU, Bosco JL, Thwin SS, Gold HT, Owusu C, Field TS, Quinn VP, Wei F, Silliman RA: Referral, receipt, and completion of chemotherapy in patients with early-stage breast cancer older than 65 years and at high risk of breast cancer recurrence. J Clin Oncol 2009, 27:4508-4514.

26. Bouchardy C, Rapiti E, Fioretta G, Laissue P, Neyroud-Caspar I, Schafer P, Kurtz J, Sappino AP, Vlastos G: Undertreatment strongly decreases prognosis of breast cancer in elderly women. J Clin Oncol 2003, 21:3580-3587.

27. Mandelblatt JS, Sheppard VB, Hurria A, Kimmick G, Isaacs C, Taylor KL, Kornblith AB, Noone AM, Luta G, Tallarico M, Barry WT, Hunegs L, Zon R, Naughton M, Winer E, Hudis C, Edge SB, Cohen HJ, Muss H, Cancer Leukemia Group B: Breast cancer adjuvant chemotherapy decisions in older women: the role of patient preference and interactions with physicians. J Clin Oncol 2010, 28:3146-3153.

doi:10.1186/1477-7819-11-286

Cite this article as: Zhang et al:: Factors associated with receipt of adjuvant chemotherapy among married women with breast cancer. World Journal of Surgical Oncology 2013 11:286.

\section{Submit your next manuscript to BioMed Central and take full advantage of:}

- Convenient online submission

- Thorough peer review

- No space constraints or color figure charges

- Immediate publication on acceptance

- Inclusion in PubMed, CAS, Scopus and Google Scholar

- Research which is freely available for redistribution 